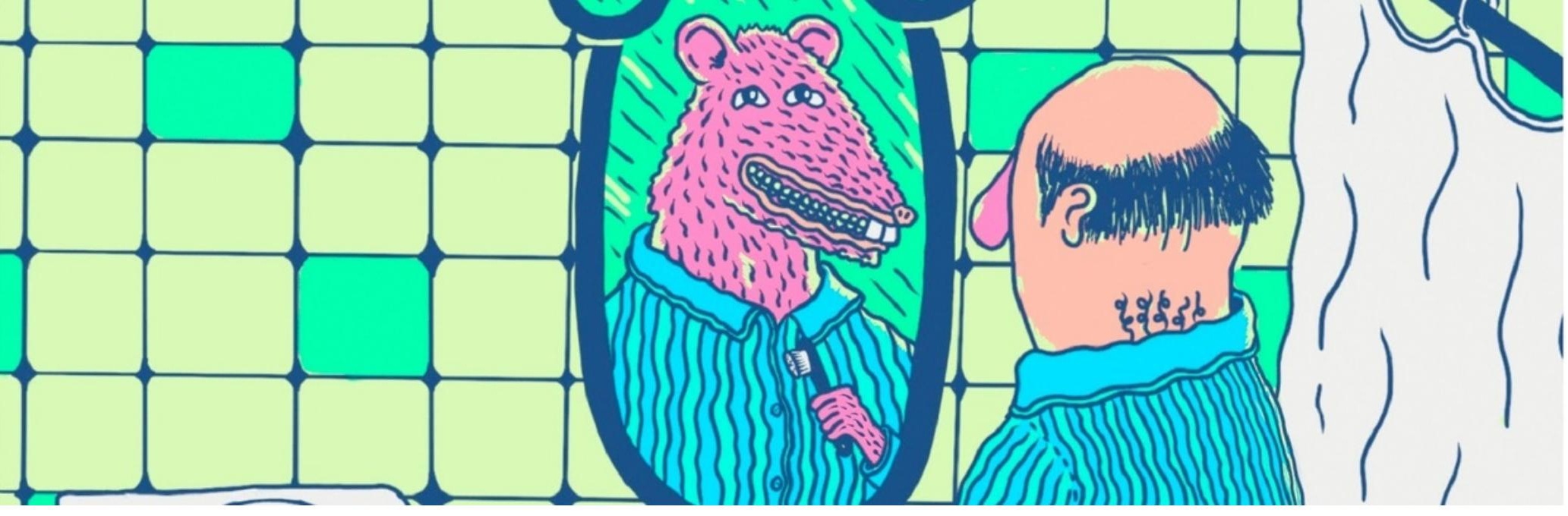

\title{
De ratones y humanos - Of Mice and Humans
}

\author{
Authors: Julieta Alcain \\ Submitted: 28. Januar 2021 \\ Published: $\quad$ 15. Februar 2021 \\ Volume: 8 \\ Issue: 1 \\ Affiliation: EGLC Journal, Argentina \\ Languages: Spanish, Castilian \\ Keywords: Data, Humans, Mice, Analysis, \\ Categories: \\ Life Sciences, Artificial Intelligence, Modeling and Simulation, \\ Medicine \\ DOI: $\quad$ 10.17160/josha.8.1.735
}

\section{Abstract:}

In most cases, experiments performed in animal models represent a valuable tool to understand human diseases. However, to a greater or lesser extent, there can be some degree of subjectivity on how scientists analyze the obtained data. We have to be especially careful to look at it as fairly as possible. Otherwise, we might see whatever each of us wants to see. In February 2013, Junhee Seok showed that mouse models poorly mimic human wound healing mechanisms. In June 2014, Keizo Takao and Tsuyoshi Miyakawa used the same data, but with a different statistical analysis, to conclude the opposite. This is their story. Previously published on: 25/6/2018 Link to the original article: https://elgatoylacaja.com.ar/derat

\section{JOSHA}

josha.org
Journal of Science,

Humanities and Arts

JOSHA is a service that helps scholars, researchers, and students discover, use, and build upon a wide range of content 


\title{
De ratones y humanos - Of Mice and Humans
}

\section{Julieta Alcain}

\author{
llustrador: Juan Puerto
}

Fecha de publicación previa: 25/6/2018

Link a la nota original: https://elgatoylacaja.com.ar/de-ratones-y-humanos/

\begin{abstract}
In most cases, experiments performed in animal models represent a valuable tool to understand human diseases. However, to a greater or lesser extent, there can be some degree of subjectivity on how scientists analyze the obtained data. We have to be especially careful to look at it as fairly as possible. Otherwise, we might see whatever each of us wants to see. In February 2013, Junhee Seok showed that mouse models poorly mimic human wound healing mechanisms. In June 2014, Keizo Takao and Tsuyoshi Miyakawa used the same data, but with a different statistical analysis, to conclude the opposite. This is their story.
\end{abstract}

Es impresionante todo lo que sabemos del funcionamiento del cuerpo humano gracias a estudios en animales. Lo primero que supimos sobre la digestión se lo debemos a los estudios en pájaros y en perros. Lo (todavía poco) que sabemos sobre conexiones neuronales es gracias a experimentos en peces, cangrejos, ratones, gatos, monos y otro montón de animales. Incluso los avances sobre enfermedades como el cáncer se apoyan en años de trabajo con ratoncitos. 
Desde la Antigua Grecia hasta hoy, la experimentación con animales nos llevó a construir un cuerpo monstruosamente enorme de conocimiento biomédico. Sin ir más lejos, una búsqueda con las palabras mouse model (es decir, ratón modelo para el estudio de patologías humanas) en la base de datos mundial de publicaciones científicas en medicina arroja nada menos que 284.129 resultados.

El hecho de que haya tantas publicaciones sobre experimentos hechos en ratones implica una gran suposición: la idea de que el animal de estudio y el ser humano se comportan de igual manera frente a determinada enfermedad. De más está decir que no hay que ser un genio para darse cuenta de que un ratón no es un ser humano, un perro no es un ser humano, ni siquiera un mono (modelo muy usado para investigar el $\mathrm{VIH}$ ) es un ser humano. A simple vista, parece un salto de lógica enorme creer que podemos extrapolar los resultados obtenidos en un ratón a un ser humano. Y lo es: las extrapolaciones deben hacerse con muchísimo cuidado. Un ratón no es un humano así como el mapa no es el territorio.

Por supuesto que hay otros fundamentos para utilizar ratones en la experimentación: muchos experimentos hechos en animales hicieron y siguen haciendo avanzar el conocimiento científico, sobre todo en el área de la salud, mientras que los estudios hechos en humanos son muchísimo más limitados en sus alcances, o directamente están prohibidos. Pero además, los ratones son pequeños, fáciles de criar, baratos y podemos manipular sus genes de manera simple. Claro, también hay fundamentos para NO utilizar ratones: ¿quiénes somos los humanos para decidir sobre la vida de otro ser vivo?

La investigación con animales no es sólo más cómoda, más fácil y más legal que la investigación sobre el cuerpo humano: bien hecha, también es más completa y nos da un panorama amplio del funcionamiento de ciertos órganos y sistemas, el comportamiento de ciertas enfermedades o el mecanismo de acción de las drogas en un organismo completo. Si volvemos a la pregunta de quiénes somos para 
hacerlo, es relevante mencionar que este tipo de estrategia también está fuertemente regulado por comités de uso ético de animales de laboratorio, que siguen bien de cerca a los investigadores, cerciorándose de que sólo usen animales cuando es estrictamente necesario y de que usen la menor cantidad posible, logrando una mirada interdisciplinaria para un desafío ético complejo.

Pero de todas maneras hay un problema aún peor: aparentemente, por mucho que tratemos de racionalizar el uso de animales en laboratorios, algo está mal, ya no éticamente, sino prácticamente. Varios de los ensayos clínicos, o sea, el momento donde se dejan las pruebas en animales para pasar a las de humanos (que también son animales) están fallando. De cada 10 drogas que ingresaron a la primera fase de ensayos clínicos entre 2003 y 2011, apenas una terminó siendo aprobada. Y la proporción es aún menor cuando nos enfocamos en las terapias contra el cáncer.

Ante esta preocupación, la solución fue hacer minería de grandes bases de datos, rehacer cálculos y responder a la pregunta con datos duros. Y pasó algo hermoso.

En 2013, el investigador Junhee Seok y sus colaboradores descubrieron algo pasmoso: ni por asomo (pero NI CERCA) se parecían los modelos animales a lo visto en pacientes humanos. Recrearon en los animales diferentes tipos de heridas y compararon entre humanos y ratones el tiempo de recuperación, pero también las diferencias a nivel genético, es decir, qué genes se expresaban más en respuesta a esas heridas (recordemos que los seres vivos tenemos muchísimos genes pero no todos están activos al mismo tiempo, la expresión es una medida de esa activación). Tanto en lo que refería al tiempo de recuperación como a la expresión de los genes, registraron lo mismo: los animales de laboratorio y los humanos no se parecen en nada. Estamos hablando de niveles de semejanza apenitas por encima de lo que podría deberse al azar. En otras palabras, si había alguito similar entre ratones y personas era pura casualidad. Con intrincadas cuentas estadísticas 
mostraron que las respuestas a nivel genético de los ratones no tienen un pepino que ver con las respuestas de los humanos.

El artículo, titulado Las respuestas genómicas en ratones imitan pobremente las respuestas inflamatorias humanas, escandalizó a la comunidad científica, a la prensa y a la opinión pública en general. El New York Times publicó un artículo en el que, sencillamente, sentencia: “(...) como resultado, años y miles de millones de dólares fueron desperdiciados en seguir pistas falsas (...)". Porque claro, el panorama era complejo. Eran muchos los trabajos, los avances biomédicos que se habían hecho sobre la base de una mentira total. Desde el principio usábamos el modelo de animales por su semejanza con el humano, pero aunque se parezcan 'por fuera', genéticamente parecía que no teníamos nada que ver.

Y así fue que vivimos durante un año y medio en pena. Crisis. Qué estamos haciendo. Cuál es el propósito de seguir llevando adelante esto. Cuál es el sentido de la vida. Pero los autores de los 284.129 trabajos hechos con modelos de ratón, claramente, no estaban muy contentos con esta conclusión, así que metieron más evidencia al debate.

En junio de 2014 se publicó otro artículo cuyo título fue Las respuestas genómicas en ratones imitan excelentemente las respuestas inflamatorias humanas. Y no sólo eso: los autores (Keizo Takao y Tsuyoshi Miyakawa) usaron LOS MISMOS DATOS que los del trabajo anterior para sacar una conclusión diametralmente opuesta. Lo bueno de tener disponibles datos crudos es que cualquiera puede verificar la veracidad de un resultado.

Takao y Miyakawa destrozaron a Seok. En principio porque no había hecho una 'selección' de genes a estudiar, con lo que cualquier método para encontrar diferencias entre ratones y humanos, pierde de vista una diferencia real por estar 'diluida' entre genes que no interesan. Por ejemplo, quizá los genes involucrados en 
Journal of Science, Humanities and Arts

February 2021

Volume 8 , Issue 1

la sanación de la herida se comportaban igual, pero genes relacionados con la capacidad de oler queso no, y el resultado de estos últimos tapaba a los otros. Pero según Takao, resulta que las intrincadas cuentas estadísticas que demostraban que los organismos no tienen nada que ver estaban mal hechas: Seok había usado un cálculo estadístico (coeficiente de correlación de Pearson) que asume que los datos cumplen ciertos presupuestos (una distribución normal y una correlación de tipo lineal). Takao usó los mismos datos, pero antes chequeó, en lugar de asumir, si cumplían esas reglas. Al ver que no, y usando el método apropiado (el coeficiente de Spearman) para un conjunto de datos de esas características, demostró cabalmente que los ratones y los humanos se parecen bastante en sus respuestas inflamatorias. Al menos, lo suficiente como para que miles de investigadores a lo largo y ancho del mundo volvieran a respirar tranquilos ( $\mathrm{y}$ a pedir plata para proyectos basados en modelos animales).

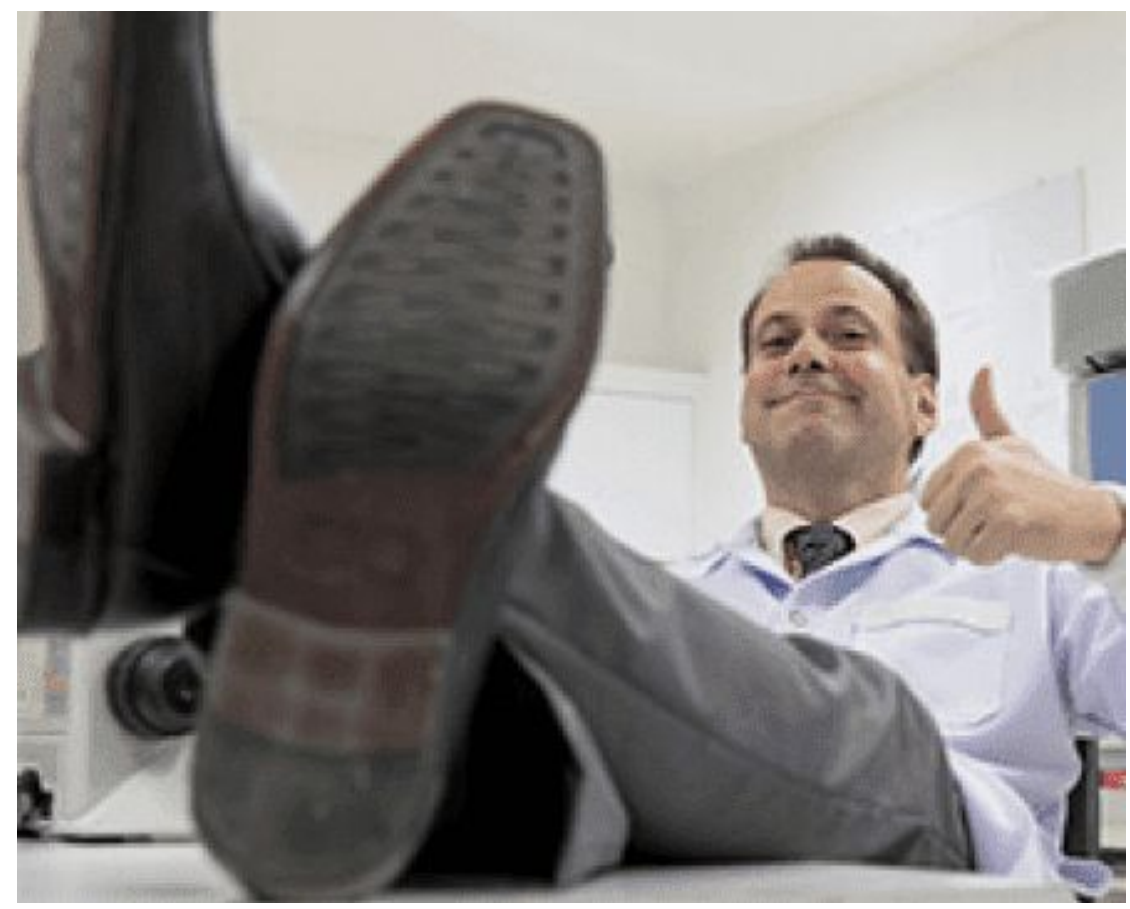

“Desde que Takao y Miyakawa publicaron su PNAS, jsoy un 74\% más feliz!” 
Pero, entonces ¿son o no son parecidos los ratones a los humanos? Más allá de toda la plata, que puede o no haber sido desperdiciada en ensayos clínicos para drogas que en animales parecían funcionar, ¿qué onda con todos los descubrimientos basados en modelos animales? ¿Qué onda con los fármacos desarrollados y aprobados como tratamientos para enfermedades? ¿Qué onda con las vacunas? ¿Es todo una gran mentira? Es evidente que algo está funcionando bien porque pudimos erradicar varias enfermedades que antes nos mataban y desarrollar terapias efectivas para muchas otras, en base a experimentos con modelos animales. También es evidente que hay que afinar la puntería a la hora de diseñar los experimentos, porque no todas las preguntas se responden con un ratón, pero es innegable la utilidad del trabajo con modelos a lo largo de la historia de la biomedicina y los avances en salud. Lo importante, además, es que estos estudios nunca están del todo terminados, las drogas están siempre en constante revisión y vigilancia, y ninguna droga nueva se aprueba si no tiene, como mínimo, la misma efectividad que la usada en la terapia hasta el momento de su aprobación.

Ciertamente, los datos no mienten. Pero tampoco 'dicen la verdad'. Los datos están ahí, son números, no dicen, a priori, nada. Este intercambio de mojadas de oreja a nivel mundial lo pone en clara evidencia. Pido disculpas, si corresponde, por la expresión 'mojadas de oreja', pero sinceramente: si publicar un trabajo que tira a la basura años de convenciones y paradigmas científicos globales con tanta liviandad no lo es, quizá refutar ese mismo trabajo con los mismos datos, en la misma revista y con prácticamente el mismo título pueda ganarse esa categoría.

Es el tratamiento de los datos lo que los hace relevantes. Es ponerlos al servicio de una hipótesis. Pero eso también es lo peligroso. Como bien ilustra este caso, los mismos datos pueden apoyar cierta hipótesis o la opuesta. Todas las evidencias pueden manipularse. Se pueden torcer a favor de las creencias de quien las mira, y ni siquiera hace falta mentir los datos para hacerlo. Ejemplos de esto hay de sobra. 
No hay consenso científico acerca de que Seok tenga razón ni de que Takao la tenga. Tampoco está claro quién tiene la última palabra, porque tal cosa no existe en la ciencia. La última palabra sólo es la última hasta que aparece una mejor explicación y desplaza a la que hasta entonces era considerada la mejor. ¿No es hermoso?

Takao no fue el único que le respondió al trabajo de Seok. Decenas de cartas fueron y vinieron entre paladines y detractores del uso de modelos animales. Entre críticas y defensas, en una de esas cartas se describe una suerte de 'pasos a seguir' a la hora de elegir de qué manera hacer un experimento, en base a la pregunta que queremos responder: ¿es necesario usar un animal o podemos hacer este experimento sacándole sangre a una persona y analizándola? Si vamos a usar un animal, ¿va a ser un ratón, una rata, un primate, un gato? Todo dependerá de la pregunta y de lo bien (o mal) que se reproduzca lo que ocurre en un humano en el animal elegido: síntomas de una enfermedad, características de un tejido, capacidad infectiva de un parásito. Los animales en investigación son importantes, y no menos importante es saber cómo elegirlos, por qué los usamos y cuándo no es necesario hacerlo.

A los científicos y científicas que trabajan con animales, por supuesto, les conviene creer que los ratones son un modelo confiable para tratar enfermedades humanas. Pero sería necio tirarle el artículo de Takao a cualquiera que critique la extrapolación de conocimiento obtenido de modelos. Sobre todo habiendo tantos medicamentos que nunca llegan a aprobarse porque, por más que dejen impecable a un ratón, en los humanos no son efectivos, lo que a las claras significa que algo estamos haciendo mal al cambiar de especie. Por el contrario, se debe seguir juntando evidencia que respalde las investigaciones, pero a la vez prestar atención a las que no las respaldan, para ser lo más cautelosos posible en las conclusiones que se desprenden. La ciencia se enriquece de este tipo de intercambio con argumentos, con fundamentos, con conocimiento. Dos personas construyen su caso y lo defienden, con tantas fundamentaciones, datos y evidencias, que elegir en quién 
creer está en cada uno, siempre que elijamos en base a los datos, y no en base a nuestro preconcepto.

En definitiva, los datos son lo que hacemos con ellos, y hay que tener especial cuidado en mirarlos con la mayor imparcialidad posible. De otra manera, vamos a ver lo que cada uno de nosotros quiera ver, siempre. O peor: vamos a ver lo que los demás quieren que veamos.

\section{Referencias}

J. Seok et al., "Genomic responses in mouse models poorly mimic human inflammatory diseases.," Proc. Natl. Acad. Sci. U. S. A., vol. 110, no. 9, pp. 3507-12, Feb. 2013.

G. Kolata, "Mice fall short as test subjects for some of human's deadly diseases," The New York Times, 11-Feb-2013.

K. Takao and T. Miyakawa, "Genomic responses in mouse models greatly mimic human inflammatory diseases," Proc. Natl. Acad. Sci. U. S. A., vol. 112, no. 4, pp. 1167-1172, 2014.

M. Hay et al., "Clinical development success rates for investigational drugs", Nat. Biotechnol., vol. 32, no. 1, pp. 40-51, Jan. 2014.

\section{About the Author:}

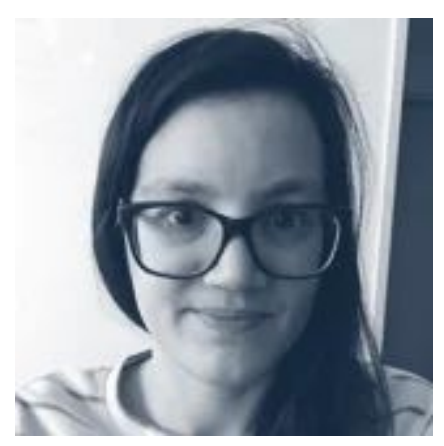

Julieta is a Biologist, PhD student, high school teacher and former (and future?) communicator during the day. Ceramist, football player and knitter at night. Intense and restless 24/7. 